\title{
Breves Considerações sobre o Curso "Práticas de Leitura e Escrita Acadêmicas em Humanidades"
}

\author{
Valéria De Marco ${ }^{1}$, Marcus Sacrini² \\ 'Departamento de Letras Modernas, ${ }^{2}$ Departamento de Filosofia \\ Faculdade de Filosofia, Letras e Ciências Humanas da Universidade de São Paulo \\ * Autor para correspondência: sacrini@usp.br
}

\section{RESUMO}

Apresentamos neste relato nossa proposta de um curso, inicialmente oferecido de modo experimental e em seguida como disciplina optativa, voltado para o treino das capacidades básicas de leitura e escrita acadêmicas. Expomos a concepção geral do curso e acentuamos a importância desse trabalho na formação dos estudantes de graduação.

Palavras-chave: Leitura; Escrita; Fichamento; Espírito Crítico; Formação.

\begin{abstract}
We present in this report our proposal of a course, initially offered in an experimental way and after as an elective class, focused on the training of basic skills of academic reading and writing. We broach the general conception of the course and we highlight the importance of such a work in the education of undergraduate students.
\end{abstract}

Keywords: Reading; Writing; Taking Notes; Critical Spirit; Education.

\section{Introdução}

O curso de graduação "Práticas de Leitura e Escrita Acadêmicas em Humanidades" surgiu da constatação das dificuldades crescentes dos alunos ingressantes em nossa faculdade (FFLCH) em lidarem de modo satisfatório até mesmo com tarefas básicas exigidas para o bom aproveitamento das disciplinas de suas áreas de estudo. A proposta foi formulada por um grupo de professores de diferentes carreiras em que ingressam os alunos de graduação da nossa faculdade. São eles: de Ciências Sociais (André Singer e Cícero Araújo), de Filosofia (Caetano E. Plastino, Marcus Sacrini e Ricardo R. Terra), de História (Marcos Napolitano), de Letras (Valéria De Marco) e de Linguística (Esmeralda V. Negrão e Ronald Beline). Almejamos integrar ao menos um docente da área de Geografia na equipe, de modo que todos os cursos de nossa faculdade tomem parte do projeto.

O caráter interdisciplinar do curso foi uma consequência natural da presença de professores de diferentes disciplinas e pautou a seleção dos cin- quenta estudantes inscritos e de dez monitores. Nas aulas, propusemos a leitura de textos de diferentes áreas das humanidades, tendo em vista a realização de algumas tarefas que permitissem aos estudantes conscientizarem-se sobre a importância de treinar as capacidades básicas de leitura e escrita. Antes de detalhar esse núcleo do curso, cabe ressaltar que montamos, no correr de 2015, duas edições experimentais dele, oferecendo-o como atividade livre. Em ambas, houve a participação de monitores, de modo que os inscritos recebessem um acompanhamento bastante cuidadoso no correr das atividades propostas. No primeiro semestre de 2015, os monitores eram doutorandos e a eles a Pró-Reitoria de Graduação, em parceria com a de Pós-Graduação, concedeu dez bolsas do PAE. No segundo semestre, foram selecionados alunos da graduação por meio do edital do Programa Unificado de Bolsas USP. Insistimos aqui no papel central dos monitores para o sucesso desse tipo de curso, que não tem como tarefa central a transmissão de conteúdos teóricos mas se serve desses últimos para treinar 
metodicamente habilidades expressivas, treino que exige então constante avaliação e direcionamento. Os cursos experimentais motivaram a criação da disciplina optativa FLF0506, oferecida no primeiro semestre de 2016. Devido à grande demanda, estamos empenhados em conseguir adesão de novos grupos de professores para ampliar o número de turmas.

\section{A Orientação Crítica do Pensar}

Gostaríamos de destacar minimamente as ideias centrais que nos moveram a desenvolver esse curso. Nosso norte é a concepção de graduação como um processo de formação crítica dos estudantes, e não de precoce especialização. Ainda que de modo muito geral, parece correto apontar que o sentido da formação em humanidades está intimamente ligado à noção de espirito crítico. Sem dúvida, muito poderia ser dito acerca dessa noção; de nossa parte, pretendemos salientar somente um aspecto definidor a ela comumente associado. O qualificativo "crítico" aqui em pauta marca um tipo particular de postura, segundo a qual não se aceitam as opiniões acerca dos temas estudados passivamente, apenas porque derivam de autoridades ou de tradições bem estabelecidas, mas se buscam as justificativas racionais que permitem sustentar o ponto de vista em questão. Aceitar uma tese criticamente significa ser capaz de compreender e avaliar as razões oferecidas para sua legitimação, tornando visíveis os intrincados movimentos argumentativos de que as concepções teóricas estudadas se compõem.

É importante destacar esse último tópico. $\mathrm{O}$ conhecimento produzido pelas humanidades exige uma orientação crítica do pensar. Afinal, uma das marcas das humanidades é a pluralidade de concepções teóricas acerca dos problemas e de práticas centrais das disciplinas. Várias são as posições em disputa nas áreas de estudo, e é comum que os consensos não sejam obtidos por verificação empírica de fatos decisivos, mas por finos debates argumentativos entre diferentes matrizes conceituais. Formar-se em humanidades, em grande medida, envolve o aprendizado de diversos paradigmas teóricos muitas vezes em conflito acerca de problemáticas similares.

Diversos questionamentos preocupam os estudantes diante desse quadro: "como entender as disputas conceituais pertinentes à minha área de estudo?", "como me posicionar diante dessa diversidade teórica?”. Para bem responder a essas questões, cabe inicialmente entender a diversidade teórica da área como fruto de diferentes estratégias de justificação racional das teses em pauta. Trata-se, nesse sentido, de compreender a complexidade inerente a certos problemas, de recusar as respostas fáceis e dogmáticas e de inserir-se na construção de debates racionais, em que as justificativas teóricas são propostas e aperfeiçoadas à luz de críticas mútuas. Dessa maneira, para formar-se satisfatoriamente no campo das humanidades, é preciso dispor de uma compreensão amadurecida acerca da diversidade de posições e de suas estratégias de justificação. E essa exigência basilar não é devidamente cumprida sem um treinamento específico de capacidades interpretativas e expressivas. Daí a importância de desenvolver recursos de ensino que favoreçam um modo específico de percorrer a graduação, de cumprir as tarefas requeridas para formar-se. Há certas atitudes, certas perspectivas interpretativas a serem fixadas no período da graduação que se constituirão justamente como o maior legado desse período: a sedimentação de um tipo particular de orientação do pensar e do agir, a qual se fortalece no correr dos cursos exatamente porque é a postura que mais permite aproveitar o que eles oferecem.

O trabalho proposto por nosso grupo de professores consiste em oferecer um treino gradual de algumas das capacidades críticas mais básicas necessárias para o cumprimento satisfatório dos cursos de graduação em humanidades. Propomos exercícios que incentivam os estudantes a voltarem sua atenção para os seus próprios recursos expressivos, avaliarem a maturidade de suas habilidades acadêmicas e sanarem algumas fraquezas então reconhecidas. Trata-se, em suma, de propor ocasiões em que os objetos comuns 
de estudo em nossos cursos de graduação (textos de autores clássicos, por exemplo) não são o centro da aprendizagem, mas apenas o pretexto para tornar visíveis as capacidades conceituais-expressivas requeridas para a boa compreensão e avaliação desses objetos de estudo. Propõe-se, assim, uma inversão do olhar estudantil, normalmente focado em tais objetos, e que deve então se voltar para as próprias habilidades básicas de compreensão e expressão. Em nossa proposta, temos destacado duas das habilidades mais básicas para o sucesso nos cursos de graduação, certamente não apenas de humanidades: a leitura e a escrita. No restante deste relato, vamos nos limitar a retomar algumas ponderações sobre a leitura acadêmica.

\section{Leitura e Escrita no Âmbito Acadêmico}

A leitura talvez seja a atividade acadêmica mais básica com a qual os estudantes se defrontam. O enorme conhecimento acumulado nas diversas áreas das humanidades é transmitido principalmente por textos de diferentes gêneros, e somente a sua leitura metódica permite a inserção aprofundada nos amplos campos conceituais de que as disciplinas estudadas se constituem. Ocorre que, por serem alfabetizados e, assim, exercerem cotidianamente a leitura em diferentes contextos práticos, os estudantes pouco refletem por si sós acerca das exigências contidas em uma leitura especificamente acadêmica. Em sentido muito geral, espera-se desse tipo de leitura, ao menos em seu nível mais básico, o estabelecimento da posição do autor acerca do tema discutido no texto em pauta. Seja em relação a um artigo, capítulo ou mesmo livro, a leitura exigida nos cursos de graduação é aquela capaz de reconstruir tanto a posição defendida no texto quanto o seu caminho expositivo aí contido. Por mais evidente que isso possa parecer, trata-se de um objetivo não imediatamente acessível para muitos estudantes habituados a certos estilos de leitura (talvez legítimos em outros contextos cotidianos) que impedem a devida compreensão das posições defendidas nos textos lidos.
Em particular, muitas vezes os estudantes leem com uma atenção seletiva ou enviesada por meio da qual destacam apenas fragmentos que contêm teses ou passagens inferenciais que já lhes são familiares, o que então os leva a abdicar de compreender novas ideias e pontos de vistas divergentes de suas crenças prévias acerca dos temas estudados. Por meio dessa atitude, muitas noções conceituais importantes são deixadas de lado meramente por soarem, à primeira vista, estranhas ou complexas demais. Incapazes de avançar em exposições que rompem com teses familiares, os estudantes limitam severamente seu aprendizado, muitas vezes reproduzindo versões simplificadas de concepções cujo cerne teórico está fora do alcance daquilo que uma leitura ingênua consegue capturar.

Contra essa atitude, trata-se de reconhecer, em primeiro lugar, que o texto acadêmico é, ao menos idealmente, um todo estruturado argumentativamente, no qual todas as partes cumprem funções específicas na realização de sua tarefa global: defender posições. Em seguida, cumpre acentuar que a boa leitura acadêmica deve ser capaz de recuperar o movimento expositivo completo do texto tal como estruturado pelo autor. Essa nos parece a perspectiva correta para enfrentar um texto acadêmico: buscar a reconstrução ordenada de todas as suas partes (e não somente daquelas que chamam a atenção, normalmente por familiaridade, do leitor) e respeitar, nessa reconstrução, as posições efetivamente defendidas pelo autor, sem misturá-las com as opiniões do leitor acerca do tema em destaque. Esse último aspecto da leitura acadêmica supõe assumir, ao menos inicialmente, uma postura de neutralidade valorativa em relação às posições defendidas no texto lido, de modo que seja possível expor tais posições sem distorcê-las por meio das opiniões prévias do leitor acerca do assunto lido. A leitura acadêmica deve envolver um primeiro momento de reconstrução valorativamente neutra da posição do autor, o que muitas vezes falta em outros tipos de leitura, nas quais é cabível posicionar-se imediatamente contra ou a favor das posições expostas. 
Por sua vez, a leitura acadêmica, assim nos parece, deve fomentar uma ocasião de compreensão respeitosa em relação à posição do autor (independentemente de discordâncias acerca das teses ali expostas), a qual deve ser recuperada em sua totalidade expositiva.

Para que a leitura acadêmica cumpra essas metas gerais, propomos técnicas que auxiliam os estudantes a tomarem consciência de seus esquemas habituais de leitura e a os aperfeiçoarem de modo ordenado. A principal técnica explorada, em diversos níveis de complexidade, é aquela dos fichamentos. Por meio dos fichamentos, almeja-se sistematizar a reconstrução dos movimentos expositivos do texto lido. Trata-se de tornar visíveis todos os passos argumentativos ali presentes, o que possibilita capturar as posições defendidas conforme a ordenação lógica planejada pelo autor, sem misturar incautamente as opiniões prévias do leitor e sem limitar-se a salientar somente aquelas partes que lhe parecem familiares. Por mais simples que um fichamento possa ser, sua prática marca a fronteira entre uma leitura descompromissada ou enviesada e uma leitura acadêmica séria, porta de entrada para a compreensão crítica das grandes concepções teóricas que demarcam o campo das humanidades. Em nosso curso, os professores expõem textos ligados a cada grande área das humanidades, e cabe aos estudantes, com a ajuda dos monitores, produzirem fichas de leitura em grau crescente de complexidade. Conforme a avaliação final dos cursos já realizados, esse treino específico dos fichamentos gera um significativo acréscimo de compreensão dos temas tratados nos demais cursos da graduação. Trata-se de uma proposta relativamente simples e que tem trazido resultados promissores.

\section{Referências Bibliográficas}

CARNIELLI, Walter A. \& EPSTEIN, Richard L. Pensamento Crítico: o Poder da Lógica e da Argumentação. São Paulo: Rideel, 2009.

FOLSCHEID, Dominique \& WUNENBURGER, Jean-Jacques. Metodologia Filosófica. Trad. NEVES, P. São Paulo: Martins Fontes, 2006.

GOLDSCHMIDT, Victor. "Tempo Lógico e Tempo Histórico na Interpretação dos Sistemas Filosóficos". In: A Religião de Platão. Trad. PEREIRA, Oswaldo Porchat \& PEREIRA, Ieda Porchat. São Paulo: DIFEL, 1963, pp.139-147.

GUEROULT, Martial "Lógica, Arquitetônica e Estruturas Constitutivas dos Sistemas Filosóficos". Trad. ALMEIDA, P. J., Trans/Form/Ação, vol. 30, n. 1, 2007, pp. 235-246.

PORTA, Mario Ariel González. A Filosofia a Partir de seus Problemas. São Paulo: Edições Loyola, 2003.

SAUNDERS, Clare et al. Como Estudar Filosofia. Trad. Figueira, Vinicius Porto Alegre: Grupo A, 2009

VELASCO, Patrícia Del Nero. Educando para a Argumentação: Contribuições do Ensino da Lógica. Belo Horizonte: Autêntica, 2010.

VIEIRA NETO, Paulo. "O que É Análise de Texto". In: LIMONGI, Maria Isabel de Magalhães et al. Seis Filósofos na Sala de Aula. São Paulo: Berlendis \& Vertecchia, 2006.

WALTON, Douglas N. Lógica Informal. Trad. FRANCO, Ana Lúcia R. \& SALUM, Carlos A. L. São Paulo: Martins Fontes, 2006.

Publicado em 05/07/2016. 